\title{
NATIONAL COUNCIL FOR SUSTAINABLE DEVELOPMENT IN MONGOLIA
}

\author{
S. Dagvadorj (Mongolia)
}

\section{Historical development of National Council for Sustainable Development (NCSD)}

Mongolia has supported the sustainable development strategies and opportunities since the 1992 United Nations Conference on Environment and Development, which gave to Mongolians a new inspiration to development strategies. This inspiration led to the development of 1996 National Development Concept, 1998 Mongolian Action Program for the $21^{\text {st }}$ Century and 2001 Regional Development Concept.

National Council for Sustainable Development (NCSD) was created in Mongolia even before the official start of MAP 21 document preparation. Before the 1996, the government structure of Mongolia does not have constituent that fulfills sustainable development by dealing with environment and development issues together in a balanced manner.

The Government established the NCSD chaired by the Prime Minister in April 1996 to oversee the development and implementation of Mongolia's sustainable development strategies. NCSD's mission is to further sustainable development efforts in Mongolia and NCSD provides overall guidance on MAP 21. The National Development Board was appointed as a Government Executing Agency for MAP 21. However, in less than a month since beginning of MAP 21 there was a change of Government and former National Development Board was disappeared.

NCSD has been revised several times with the reorganization of the Government structure since 1996. There was also need to reorganize the NCSD to extend multi-stakeholder participation in implementation of NCSD decisions incorporating NGOs, private sector and academicians and also involving different level of government officials.

The organizational structure of NCSD has been changed four times since its creation:

i. in April 1996 there were 13 members, mostly high level government officials (6 Cabinet Ministers, 3 vice-ministers, 3 local Governors, and Head of International Organization Department of the Foreign Relations Ministry); 
ii. in May 1998 there were 18 members including representatives from the Parliament, NGOs and private sector (3 Chairs of Parliament Standing Committees, 6 Cabinet Ministers, 4 local Governors, Head of Cabinet Secretariat, Head of International Organization Department of the Foreign Relations Ministry, Sustainable Development Advisor of UNDP CO, Head of Business Council for Sustainable Development, and representative from NGOs),

iii. in February 1999, added the local Governors to the previous composition of NCSD and the MAP 21 National Coordinator became as a secretary of NCSD.

iv. in May 2002, which presents the current NCSD including representatives from NGOs, private sector, local governors and scientific institutions?

Thus, if in previous 2 modifications the NCSD appeared to be almost a replication of the Cabinet, according to the last 3 changes the membership of NCSD has been enlarged inviting representatives from Parliament, NGOs, private sector and scientific institutions.

\section{Status of NCSD}

The NCSD is a non-staff multi-stakeholder participatory body. In other word, NCSD does not have its own Secretariat, the MAP 21 Project Implementation Unit (PIU) headed by the Secretary of NCSD and the National Programmed Coordinator serves as a Secretariat of NCSD. Currently, the coordinating agency is the Ministry of Finance and Economy and the implementing Agency is the Ministry of Trade and Industry for MAP 21. The Minister of Trade and Industry holds the position of the National Program Director of the Mongolian Action Program for the 21 st Century. At the same time, the National Program Coordinator of MAP-21, who is also the Secretary of the NCSD, provides coordination between the ministries regarding sustainable development issues and coordinates between the government and public. MAP 21 PIU as a Secretariat of NCSD consults and articulates with wide range of stakeholders prior to working groups and NCSD meetings and prepares draft of NCSD decisions. MCWG meeting finalizes the agenda and draft of NCSD decisions.

NCSD of Mongolia was given a clear mandate to coordinate and provide overall guidance on MAP 21 development process and its implementation. NCSD provides policy direction to the line Ministries, Project Implementation Unit and Aimag Governments and advises the Chair of the State Great Khural (Parliament Speaker) and the President of Mongolia on sustainable development policy and 
strategy, on the next steps in building the new management system related to the sustainable development and on policies that foster Mongolian participation in regional and Earth sustainable development process.

\section{Multi-Stakeholder Participation of NCSD}

The NCSD is comprised of different stakeholders from the government, NGOs and private sector. In general, membership to the NCSD was developed in such a way that it would not change even if there are to be changes in the Government of Mongolia as, for example, the Prime Minister of Mongolia is automatically appointed as the Chairman of the NCSD. Consequently, deputy chairs and some of members, who hold the position of Parliament Member and Minister, will be replaced too.

Mongolia has experienced different approaches to extend multi-stakeholder participation in implementation of MAP 21. As we have seen from development stages of NCSD, the multi-stakeholder participation in NCSD continues to be extended during the implementation stage of MAP 21 . We recognized the need to include various representatives from the various institutions as the activities of the MAP 21 were widening and covering all sectors and population group. Thus, the NCSD has extended its composition and activities.

The country's sustainable development strategy (MAP 21) was developed from 1996 to 1998, under the leadership of Mongolian NCSD, which was consisted of pure government officials. However here we should note that the NCSD provided the multi-stake-holder participation in the formulation of MAP 21. The NCSD supported the development of 21 aimags' and capital city action programmed (AAPs) defining development challenges and priorities at a far more local level than is done in the national strategy.

\section{Current composition of NCSD}

The current NCSD has about 30 members, including 3 chairpersons. The Prime Minister of Mongolia chairs the NCSD of Mongolia. Ministers of Finance and economy, Nature and Environment and Trade and Industry hold the position of Deputy Chairs of NCSD.

In the composition of the NCSD include 4 Parliament members, Senior Advisor on economic issues to the Prime Minister, 6 Cabinet Ministers and the others, representing public, private, local and non-governmental organizations.

The four heads of the Standing Committees of the Parliament who have become members of the Council are chairs of Economic Policy Standing Commit- 
tee, Budget Policy Standing Committee, Social Policy Standing Committee and Environment and Rural Development Standing Committee. These appointments have been the strongest points in the composition of the NCSD due to their direct involvement in the implementation of SD in Mongolia. On the other hand, appointment of the four chairs of the Parliament Standing Committees to the membership of the NCSD gives an opportunity to integrate economic, social and environmental issues and is helpful to reflection of decisions of the NCSD at the decision making level.

Except the ministerial positions, representatives of the following ministries are members of the NCSD: Finance and Economics, Nature and Environment, Social Welfare and Labor, Agriculture and Food Industry, Infrastructure, Health, Education, Culture and Science, Justice, Foreign Relations to provide the sect oral link.

The new NCSD also have the representatives of NGOs which present environmental organizations, women's groups, youth association, children's organization, and trade unions. Most of the NGO members include in working groups as leading experts in relevant fields. It is due to the lack of experience and commitment from the government representatives at both local and national levels in involving NGOs in decision-making. In Mongolia, NGOs are spring up freely only since 1990. Therefore, government agencies and NGOs have no tradition and skills of cooperation. Only now starting to have some experience. NGOs and the private sector are included mostly in the working groups but not in all ESEC with the decision-making status at local level. There is still need to include more representatives from NGOs for the successful implementation of the programmed and from scientific institutions to assess and outline the development in the country.

20th May 2000, the new NCSD has organized its first meeting. It was very fruitful meeting. The main objectives of this meeting were (I) to introduce new members with activities related to the sustainable development and NCSD, (ii) to discuss the on-going activities and further plan for WSSD preparation at global, regional and national level and (iii) to define the problematic issues related to the sustainable development at the national level. Discussing these issues, the NCSD made the following main decisions: (I) the NCSD will be preparatory committee for the WSSD, (ii) to establish Mongolian National Institution of Sustainable Development to support the sustainable development at national level, (iii) to improve multi-stakeholders cooperation and strength NCSD's activities by dividing NCSD into 2 main sub-councils; one is NGOs' and other one 
is Scientific and lastly, to focus NCSD's activity on problematic issues of the country.

\section{NCSD at local level}

Organizational structure of NCSD at local level depends on geographical and topical basis. At the local level all 21 aimags have local branches. Fulfilling the NCSD's decision the Aimag Sustainable Development Actions (ASDAs) facilitated setting up of the NCSD local branches headed by the Aimag and Capital City Governors - Economic, Social and Environmental Committees (ESECs) to guide the implementation of Aimag /Capital City Action Programmers. The ESECs were established by the resolution of local Citizens' representatives that have also approved the membership of the committees.

The ESECs are composed of members of local government, citizens' representatives, local and national NGOs and business community. A typical ESEC is comprised of 9-12 members of the local administration and 1-5 representatives of NGO's and the private sector depending on aimag specifics. Under each ESEC there are three to four working groups specializing on the four Agenda 21 issues - economic, social, environment and civil society participation. The NGOs and private sector representatives included not in all ESEC with the decision-making status at local level.

\section{NCSD' and new activities for sustainable development}

Until now, the NCSD was concentrated more on the formulation of sustainable development programmers. Now the NCSD will act as a catalyst and coordinator promoting and supporting the implementation of MAP 21 across country and

Key sectors. For this purpose, the NCSD will shift its focus from developing a national sustainable development strategy to promoting implementation of this strategy through national and international partners - supporters for appropriate MAP 21 demonstration projects including curriculum reform, and helping images to find applicable support and information for the implementation of their AAPs.

The NCSD will also help to promote longer-term implementation MAP 21 through support for ongoing public awareness campaigns organizing workshops and seminars, the development of effective participatory systems of monitoring MAP 21 and AAPs' implementation and by establishing a permanent structure within the Government responsible for promoting and monitoring implementation of MAP 21. 
The NCSD will pay relevant attention to international cooperation in building up regional and sub regional consensus on sustainable development issues including future elaboration of existing relationship with UN CSD, Earth Council, UNDP, APNCSD, and other international organizations, donor and neighboring countries.

Cooperation with NGOs, private sector and academics are still need to be strengthened in the work of the NCSD at both national and local levels. Specially, the multi-participation is not provided enough at local level. Need to extend multi-stakeholder participation in implementation of NCSD decisions at local level.

NCSD and the Project Implementation Unit for MAP 21 are focusing their activities by the following directions towards implementation of sustainable development programmed:

1. In Mongolia sustainable development concepts is not deeply considered and this process has been undergoing at the same time as the transformation of the system to market oriented one. As such, this makes difficult to understand nature of sustainable development concept in full term. Although the MAP 21 and Aimag Action Programmers of Mongolia are developed and in certain stages implemented, it should be assumed that the sustainable development activities in Mongolia are in a starting stage. Nonetheless, recognizing the importance of the concept is significantly important that this very moment is crucial for Mongolia's future and its progression. Considering this fact, the Mongolian President has given an assignment to the Government to formulate a new concept of development revising the existing policy documents related to the development. By now, NCSD and Project Implementation Unit are working on the draft of the Sustainable Development Concept. This policy document will be determining the Mongolian National Policy on Sustainable development.

2. Monitoring mechanisms for the implementation of MAP 21 and the global Agenda 21 have not been clearly determined yet. In other words, the means of measurement and indicators to monitor the progress of MAP 21 ant its implementation have not been defined at national and local level. There is need to establish an institution to support the sustainable development in Mongolia at national level. Therefore, NCSD is planning to establish a National Center (or Institute) for Sustainable Development of Mongolia to provide immediate support to the Government in formulating its sustainable development strategies, policies, programmers and projects and in their implementing, monitoring and evaluation and to organize training, research and management of $\mathrm{SD}$, promote 
implementation of clean technology projects and establish database on SD issues.

The immediate objectives are:

- Formulation of sustainable development strategies, policies, programmers and projects according to the new concepts of Johannesburg WSSD2002, Millennium Declaration and Earth Charter and Mongolia's National Development concepts;

- Training on sustainable development subjects;

- Ecological clean technology transfer;

- Sustainable development information networking;

- International cooperation;

- Integration of the goals and principles of sustainable development into the national and local plans and programmers of key sectors;

- Effective monitoring of MAP21 Implementation;

- Support for implementation of the Aimag Action Programmers; and

- Enhanced public awareness and sustainable development education in support of MAP21.

3. Following the Mongolian Sustainable Development Strategies and Action Programmed, we are planning to establish a Clean Technology Center (CTC) by the main purpose to raise environmental awareness and foster improved environmental behavior in the consumers and producers, to introduce with clean technologies, learning the full environmental impact and to expertise the clean technologies before the identification and implementation in the industries. CTC will provide the expertise, experience and knowledge necessary to ensure Environmental sustainability, business viability and the services such as consultancy, legislation, financial aid, audits, training and clean technologies.

4. The main priorities of the actions will be focused on:

- Elaboration of Regional Sustainable Development Programmers, in particular starting with Eastern Regional Sustainable Development Programmed as demonstration for other regions in accordance with the concept of Regional Development of Mongolia.

- Elaboration of some selected Sound Sustainable Development Programmers as demonstration for other sums.

- Formulation and implementation some projects specially in field $6 \mathrm{f}$ desertification, deforestation, land and water resources management, ecological clean production with assistance of donors.

- Implementation of projects specially in Eastern Region in cooperation with neighboring prefectures of China and with assistance of bilateral 
and multilateral donors, including: Biodiversity projects, Formation of a Sub-regional Cooperation Committee, Formation of a Sub-regional Chamber of Commerce, Open Arxan Border Port for Regular Trade, Technical cooperation on Agriculture and Animal Husbandry, Market potential of Green Food, Market Study for Mongolian Minerals, Study into Environmental and Economic impacts of Mining in Mongolia, Comprehensive Tourism Development Projects for Eastern Mongolia, Construct a Bridge Across Halhin Gol, Improving Road Transport for Tourism, ArxanChoibalsan Railway, Study on Potential for Producing Green Power in Eastern Mongolia etc.

\section{NCSD's preparation for the World Summit}

The NCSD stressed the importance of early and effective preparations for the 2002 review and assessment of progress in the implementation of the Agenda21 to ensure high quality inputs to this process.

1. The following are the done activities until now:

- Mongolia started its preparatory activities from October 2000 and UNCSD Guidelines have been followed in the course of preparatory activities. Preparation to the WSSD has commenced with the establishment of the National Preparatory Committee in December, 2000, headed by Deputy Chair of the NCSD and Minister for Industry and Trade. The new NCSD, which established in May 2002, now became a Preparatory Committee by the decision of NCSD's first meeting.

- Sustainable development visions for the 21 st century was organized in the form of essays competition where people form 7 to 65 years of age including high school students, local government officials, unemployed, university students, private sector employed, pensioners and teachers have participated. 15 essays were selected during the essays competition and 20 posters have been selected during the Children's Agenda 21 posters competition.

- Also, much attention was given to the awareness raising activities at national and local levels organized in the forms of national, regional, and local seminars, workshops, training courses. Regular weekly National Radio Programmed on SD, TV Programmers have been broadcasted and Newsletter on SD has been published once in a two months period. Also MAP 21 publishes articles on the WSSD in daily newspapers. 
- "National report of Mongolia on Sustainable Development Achievements Since the Rio Summit of 1992" summarizes the progress, achievements and obstacles in Mongolia in achieving the goal of sustainable development that was agreed during the United Nations Conference on Environment and Development held in Rio de Janeiro in 1992. The report covers issues specified in the Earth Council Guidelines. Wide multi- stakeholder participatory approach was used in preparation of the report and working groups headed by high rank governmental officials have been involved in preparation of the National assessment report. This National report was approved by National Assessment Forum on Sustainable Development in August.

2. The following are the main planned activities regarding the advocacy to WSSD that should be done before the WSSD:

- Prepare and conduct radio and TV serials, publish articles in the NCSD newspapers and publish booklets, leaflets, brochures on WSSD,

- Conduct series of round table discussion for WSSD involving decision makers, NGOs, scientists and other participants,

- Initiate "WSSD preparation" campaign among students,

- Participate in the meeting at international level and exchange experiences and develop partnership with the world,

- Organize national and western regional seminars on sustainable development issues. 